International Review of Social History 43 (1998), Supplement, Pp. 145-165

(C) I998 Internationaal Instituut voor Sociale Geschiedenis

\title{
Historical Inference and Event-Structure Analysis
}

\author{
LARRY J. GRIFFIN and ROBERT R. KORSTAD
}

\section{INTRODUCTION}

Event-structure analysis (ESA) is a member of a family of formal analytic procedures designed to analyze and interpret text, in particular the temporal sequences constituting the narrative of a historical event. Its basic purpose is to aid the analyst in "unpacking" an event - that is, in breaking it into constituent parts - and analytically reconstituting it as a causal interpretation of what happened and why it happened as it did. ${ }^{1}$ ESA focuses on and exploits an event's "narrativity" - its temporal orderliness, connectedness and unfolding - thereby helping historians and social scientists infer causal links between actions in an event, identify its contingencies and follow their consequences, and explore its myriad sequential patterns. Unlike most other formal analytical techniques, it is completely nonnumeric and non-statistical: ESA's value is largely heuristic and centered on how it relentlessly probes the analyst's construction, comprehension and interpretation of the event. ${ }^{2}$

More firmly and self-consciously than do most formal analytical procedures, ESA partially bridges the often damaging methodological chasm separating narrative history and generalizing social science. On the one hand, it borrows from formal social science methodology several features, including

(a) explicit deployment of theoretical concepts and hypotheses about social life;

(b) application, development and validation of causal generalizations;

(c) use of replicable procedures of analysis.

I. On "causal interpretation", the best source remains Max Weber, The Methodology of the Social Sciences (New York, 1905; reprinted 1949), pp. 113-188, esp. 169. On "unpacking" events, see Philip Abrams, Historical Sociology (Ithaca, 1982), pp. 196-226, a remarkably rewarding work for any scholar interested in events, narrative and the history-sociology dialogue. The vast literature on these and similar topies is quite useful. Much that is ditectly relevant to formal narrative analysis generally and ESA particularly is referenced in Larry J. Griffin, "Temporality, Events, and Explanation in Historical Sociology: An Introduction", Sociological Methods and Research, 20 (1992), pp. 403-427; idem, "Narrative, Event-Structure Analysis and Causal Interpretation in Historical Sociology", American Journal of Sociology, 98 (1993), pp. 1094-1133; and idem, "How Is Sociology Informed by History?", Social Forces, 73 (1995), pp. 1245-1254. Foundational references to eventstructure analysis are contained in this essay's annotated bibliography.

2. ESA and other formal analytical strategies have been systematically compared in Larry J. Griffin and Charles Ragin, "Some Observations on Formal Qualitative Analysis", Sociological Methods and Research, 23 (1994), pp. 4-21. 
By forcing the user to be meticulous in the construction of narratives, to reason causally about unfolding temporal sequences, and to be clear about the bases of causal and interpretive judgements, ESA lays bare the investigator's understanding so starkly - literally, as will be seen, as a diagram of the logic of action - that insights into causal connectedness and significance are intensely sharpened.

On the other hand, ESA mimics in important ways how many historians and historically-oriented social scientists, although themselves drawing on less formal analytical strategies, actually reason to infer causality and meaning from an event. Thus, it requires analysts to

(a) situate events in their historical and cultural contexts and then capitalize on contextual knowledge for explanatory and interpretive purposes;

(b) focus on actors and on social action, thereby fostering appreciation and comprehension of agency; that is, of how women and men actively mold, if in ways they do not always foresee or necessarily wish, their world;

(c) evoke "imaginative reconstruction" of the actor's world and her/his motives, strategies and understandings; ${ }^{3}$

(d) view the precise unfolding of an event as of cardinal importance to its interpretation;

(e) maintain, through the question-and-answer routine illustrated below, fidelity with the interrogatory spirit undergirding much historical reasoning by requiring the analyst to "interrogate" and "cross-examine" events for evidence of causal significance; ${ }^{4}$

(e) adopt the understanding of historical events as configurational, contingent happenings characterized by what philosopher-historian Dale Porter labels "the emergence of novelty";

(f) rely on their substantive judgement and interpretive skill rather than on prefigured (and thus historically "inflexible" or "static") theoretical, logical or statistical algorithms or rules.

ESA's unique analytical efficacy, then, resides in the fact that its very logic

3. Samuel Beer, "Causal Explanations and Imaginative Re-enactment", History and Theory, 3 (1963), pp. 6-29.

4. "Interrogate" is from E.P. Thompson, The Poverty of Theory and Other Essays (London, 1978), pp. 25-50; "cross-examine" is from Marc Bloch, The Historian's Craft (New York, 1953), p. 64.

5. Dale Porter, The Emergence of the Past: A Theory of Historical Explanation (Chicago, 1981), p.

3. ESA's developer, sociologist David Heise, expresses much the same sentiment when he states that one of the consequences of particular actions are on occasion the production of "new and meaningful sequences of events"; see his "Modeling Event Structures", Journal of Mathematical Sociology, 14 (1989), pp. 139-169 (the phrase quoted is on p. 14I). Historical contingency has many meanings, but the one that is perhaps best suited to ESA has a temporal basis. Succinctly expressed, it is that prior action often conditions, but does not necessarily determine, subsequent action. One of the most powerful pleas for placing contingency at the very heart of historical analysis is found in Gordon Leff, History and Social Theory (Garden City, NY, 1971), pp. 42-90. 
of operation - that is, in what it does and what it demands of the analyst synthesizes social science and historical methodologies while also empowering each to speak (as it were) with its own "voice". As we demonstrate later in the essay, this synthesis is seen in research practice both through (i) ESA's integration of the theoretically/empirically general and the historically particular so thoroughly as to render their differences largely moot, and (ii) its merger of two modes of inquiry often juxtaposed against each other, explanation and interpretation; with ESA, analysts explain as and because they are compelled to interpret, and they interpret as and because causal explanation is demanded. ${ }^{6}$ Because of this methodological "dualism", finally, inferences reached with ESA, though generally interpretive in nature, are strictly replicable. Critics know exactly the causal interpretations, and (often) the logical, empirical and theoretical reasons for them, and can directly challenge any aspect of the analysis, from the selection and written description of actions to be analyzed to their imputed significance and causal connectedness.

\section{WHAT ESA DOES}

To illustrate ESA's basic operations and practical effectiveness, we use a slice of the history of the successful United Cannery, Agricultural, Packing, and Allied Workers Union (UCAPAWA) organizing drive at the R.J. Reynolds (RJR) Tobacco plant in Winston-Salem, North Carolina, from I94I to 1944. The local that resulted from that drive, Local 22, was built and largely sustained by the collective actions of African-American workers, especially women, who made it the primary vehicle for advancing the racial aspirations of Winston-Salem's African-American working class. Incessantly hounded by RJR, damagingly red-baited in the late 1940s, and shunned by white workers, the local lost its contract with RJR in 1948 and disbanded in 1951. ${ }^{7}$

6. Griffin and Ragin, "Some Observations on Formal Qualitative Analysis".

7. The most extensive history of Local 22 is Robert R. Korstad, "Daybreak of Freedom: Tobacco Workers and the CIO, Winston-Salem, North Carolina, 1943-1950" (unpublished Ph.D. dissertation, University of North Carolina at Chapel Hill, I987). The local has been the subject of numerous publications; see, for example Robert R. Korstad and Nelson Lichtenstein, "Opportunities Found and Lost: Labor, Radicals, and the Early Civil Rights Movement" Journal of American History, 75 (1988), pp. 786-811, and Larry J. Griffin and Robert R. Korstad, "Class as Race and Gender: The Making and Breaking of a Union Local in the Jim Crow South", Social Science History, 19 (1995), Pp. 425-454. Some of the analysis we report here first appeared in Griffin and Korstad, "Class as Race and Gender", and we occasionally paraphrase from that publication. Most of the historical information about Local 22 comes from public newspapers, union newsletters and document collections, federal government reports from several different agencies, and oral histories of participants and other knowledgeable sources. For precise documentation, see Korstad, "Daybreak of Freedom" and Griffin and Korstad, "Class as Race and Gender". The important and growing historical literature on race, gender, class and unionization in the US South has been recently reviewed by Dolores Janiewski, "Southern Honor, Southern Dishonor: Managerial Ideology and the Construction of Gender, Race, and Class Relations in Southern Industry", in 
On the eve of the union drive in 194I, RJR operated the largest tobacco manufacturing facility in the world, employing 12,000 unorganized workers. The majority of its workers were African Americans of both sexes, and RJR had long manipulated racial and gender divisions among its workers to thwart unionization. But the UCAPAWA, a left-leaning union affiliated with the $\mathrm{ClO}$, had experienced real, if limited, success in organizing black industrial workers in the South in the late I930s and moved into WinstonSalem to organize RJR's black workforce in late 194I. Our ESA illustration begins at this point and continues through the first significant collective action by African-American workers in June 1943. In conventional narrative form, here, very briefly, is what happened:

Using pre-existing African-American organizations, especially the church, UCAPAWA organizers met with RJR's African-American workers and established the all-black Tobacco Workers Organizing Committee (TWOC) in 1943. TWOC members were strategically placed throughout RJR's productive processes, and the TWOC seized onto both the economic and racial hardships of workers and the war-induced tight labor market to generate support for the union. In the summer of 1943 the rising cost of living and a company directive to speed up production intensified the chronic resentments of RJR's black workers. The ramifications of the speed-up became of immediate concern on the shop-floor on June 17 , when an African-American stemmer was belittled by her supervisor for being behind in her work. Just as black women workers, some of them TWOC members, began to discuss the possibility of a protest strike, another African-American worker died on the shop-floor, reportedly after his white foreman refused to let him go home or get medical attention. The TWOC women then spontaneously staged a sitdown strike, which quickly spread. Though the UCAPAWA did not call for a large strike, other African-American workers then also walked off their jobs in solidarity, and, after sustained work stoppage, about six thousand, eight hundred of them (perhaps two-thirds of RJR's black workforce) joined the TWOC.

For use in ESA, this narrative must be condensed and expressed as a chronology consisting of a series of tightly-sequenced short descriptive statements that, in the analyst's interpretation, essentially defines the incident for formal analysis. Because ESA is essentially a heuristic aid, however, the analyst should use as much historical information as she or he has in structuring and interpreting the event; as will be demonstrated below, she or he is in no way limited to the actions contained in the formal chronology. Although the software implementing ESA, ETHNO (for "ethnographic analysis"), will accept and process virtually any type of statement, analysts will better harness ESA's "action-centeredness" if they use active voice throughout in the chronology. (As ETHNO diagrams the analyst's understanding of the event's logical structure, it abbreviates the action verb; we often use the

Ava Baron (ed.), Work Engendered: Toward a New History of American Labor, (Ithaca, NY, 1991), pp. 70-91, and Rick Halpern, "Organized Labour, Black Workers and the Twentieth-century South: The Emerging Revision”, Social History, 19 (1994), pp. 361-383. 
abbreviations in the text as a form of shorthand. $)^{8}$ For the purposes of this exposition, we have reduced the above narrative to the following nine actions:

I. Tar: UCAPAWA/CIO target RJR's African-American workers for unionization.

2. Mee: African-American workers meet with UCAPAWA organizers about unionization.

3. For: UCAPAWA forms all-black TWOC to include strategically placed workers.

4. Spe: RJR speeds up production process.

5. Abu: White foreman abused African-American female for being behind in her work.

6. Die: African American dies on shop-floor allegedly after white foreman refused to permit worker either to leave or to get medical assistance.

7. Sit: African-American female stemmers sit down, stopping production.

8. Stk: Thousands of African-American workers strike.

9. Joi: Almost 7,000 African-American workers join TWOC.

This brief chronology serves as the input into ETHNO, which then transforms it into a series of "yes/no" questions where, quite literally, the analyst is asked if a temporal antecedent ("or a similar event") is required for the occurrence of a subsequent event. ETHNO uses the analyst's responses to diagram a logical structure of action displaying the imputed causal influence and connectedness of all sequences in the chronology. Analysts are strongly advised to keep a written log of ETHNO's questions, their answers and the reasons for their answers. This is essential for subsequent replication and is of immense benefit as the analyst constructs his or her interpretation of the event. Our $\log$, which lists the questions and answers for this analysis, is presented as Table I.

ETHNO first queried us about the relationship between the first two actions in the chronology (see Table I). The exact wording of its question was: "Does 'Mee: African-American workers meet with UCAPAWA organizers about unionization' require 'Tar: UCAPAWA/CIO target RJR African-American workers for unionization' (or a similar event)?” For reasons that we discuss later, our response was "Yes", and ETHNO linked the two actions ("target" = "Tar"; "meet" = "Mee") with a line indicating a direct causal tie between an antecedent action (now understood as a cause)

8. Generally, the statements in the chronology should conform as closely as possible to ETHNO's constraints: (i) statements should be limited to one line of text (the second line of a two-line description is read by ETHNO as a new action), and (ii) the first word of the statement should be the subject of the sentence (and the actor) and the second word, the verb connoting action. Departures from these rules, though easily made (as we do with the abbreviations), can sometimes lead to needless confusion. 


\section{Table I. Questions and answers for Local 22 sequence}

Q.1 Does "African-American workers meet with UCAPAWA organizers about unionization" require "UCAPAWA/CIO target RJR's African-American workers for unionization" (or a similar event)?

Answer: Yes

Q.2 Does "UCAPAWA forms all-black TWOC to include strategically placed workers" require "African-American workers meet with UCAPAWA organizers about unionization" (or a similar event)?

Answer: Yes

Q.3 Does "RJR speeds up production process" require "UCAPAWA forms allblack TWOC to include strategically placed workers" (or a similar event)?

Answer: No

Q.4 Does "RJR speeds up production process" require "African-American workers meet with UCAPAWA organizers about unionization" (or a similar event)?

Answer: No

Q.5 Does "RJR speeds up production process" require "UCAPAWA/CIO target RJR's African-American workers for unionization" (or a similar event)?

Answer: No

Q.6 Does "White foreman abused African-American female for being behind in her work" require "UCAPAWA forms all-black TWOC to include strategically placed workers" (or a similar event)?

Answer: No

Q.7 Does "White foreman abused African-American female for being behind in her work" require "African-American workers meet with UCAPAWA organizers about unionization" (or a similar event)?

Answer: No

Q.8 Does "White foreman abused African-American female for being behind in her work" require "RJR speeds up production process" (or a similar event)? Answer: Yes

Q.9 Does "White foreman abused African-American female for being behind in her work" require "UCAPAWA/CIO target RJR's African-American workers for unionization" (or a similar event)?

Answer: No

Q.10 Does "African American dies on shop-floor allegedly after white foreman refused to permit worker either to leave or to get medical assistance" require "UCAPAWA forms all-black TWOC to include strategically placed workers" (or a similar event)?

Answer: No

Q.11 Does "African American dies on shop-floor allegedly after white foreman refused to permit worker either to leave or to get medical assistance" require "White foreman abused African-American female for being behind in her work" (or a similar event)?

Answer: No

Q.12 Does "African American dies on shop-floor allegedly after white foreman refused to permit worker either to leave or to get medical assistance" require "African-American workers meet with UCAPAWA organizers about unionization" (or a similar event)?

Answer: No

Q.13 Does "African American dies on shop-floor allegedly after white foreman refused to permit worker either to leave or to get medical assistance" require "RJR speeds up production process" (or a similar event)?

Answer: No 
Table I. cont.

Q.14 Does "African American dies on shop-floor allegedly after white foreman refused to permit worker either to leave or to get medical assistancen require "UCAPAWA/CIO target RJR's African-American workers for unionization" (or a similar event)?

Answer: No

Q.15 Does "African-American female stemmers sit down, stopping production" require "UCAPAWA forms all-black TWOC to include strategically placed workers" (or a similar event)?

Answer: Yes

Q.16 Does "African-American female stemmers sit down, stopping production" require "White foreman abused African-American female for being behind in her work" (or a similar event)?"

Answer: Yes

Q.17 Does "African-American female stemmers sit down, stopping production" require "African American dies on shop-floor allegedly after white foreman refused to permit worker either to leave or to get medical assistance (or a similar event)?

Answer: Yes

Q.18 Does "Thousands of African-American workers strike" require "AfricanAmerican female stemmers sit down, stopping production" (or a similar event)?

Answer: Yes

Q.19 Does "Almost seven thousand African-American workers join TWOC" require "Thousands of African-American workers strike" (or a similar event)? Answer: Yes

and a subsequent action (now understood as a consequence). Diagramed, the causal assumption is:

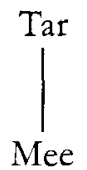

We also said "Yes" to question 2 ("Does 'For: UCAPAWA forms all-black TWOC to include strategically placed workers' require 'Mee: AfricanAmerican workers meet with UCAPAWA organizers about unionization' [or a similar event]?"), and again ETHNO directly connected the two actions as follows:

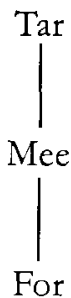


We responded "No" to the next three queries about the relationships between the "Spe: RJR speed-up" and its three antecedents in the chronology ("Tar", "Mee", "For"). Rather than tying "Spe" to any of its temporal antecedents, then, ETHNO instead placed it at the diagram's logical (not temporal) origin, indicating that, in our interpretation, the speed-up was exogenous (and unrelated) to what came before it in the chronology.

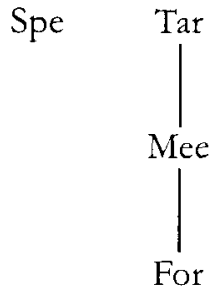

The next two queries asked about possible causal ties between the "white foreman's abuse" ("Abu") and two of its temporal antecedents ("TWOC formation" and the "meeting"). We answered "No" to both questions, as we did to the ninth query about the relationship between "the abuse" and UCAPAWA/CIO's racially-specific "targeting" strategy. Our response to the eighth question asking if "RJR's speed-up" ("Spe") was necessary for the "abuse of a slow worker" ("Abu"), however, was positive. Thus having moved through the five actions in the brief chronology and answered nine questions about relationships between those actions, we have imputed the following structure of action to what had happened in the UCAPAWA organizing drive at RJR as of mid-June 1943:

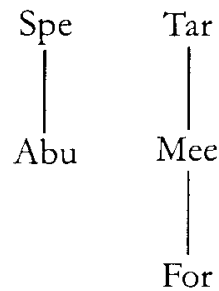

Although quite simple at this stage in the analysis (because the queries have thus far pertained only to the very early history of the still nascent local), the diagram is nonetheless instructive for two interdependent reasons. First, it portrays our causal imputations and our assumptions about how and why the actions are linked as they are, or are not linked at all. Because this feature is at the heart of ESA's utility, we discuss it at greater length in the next section. Second, its very structure has substantive meaning. Building on E.P. Thompson's insight that "(a)ny historical moment is both a result of prior process and an index towards the direction of its future flow ${ }^{n,}$, the

9. The deft phrase is from Thompson, The Poverty of Theory, p. 47. 
analyst can examine the diagram to comprehend better both how the past conditioned the "present" and how the "present", in turn, shapes the range of "future" possibilities and alternatives.

At the precise point in the local's still unfolding history captured by the diagram above (mid-June 1943), for example, a union organizing committee - composed of strategically situated African-American workers - was in place as a structural resource to be activated at any moment by aggrieved workers in their continuing organizing campaign and/or simply as an expression of the job-related discontents of black employees. This fact contextualizes, and thus gives a particular meaning to, the second stream of action - the speed-up induced abuse of an African-American worker by her white supervisor. The two streams of actions (or, as in the case of "TWOC formation", the ongoing institutional consequence of prior actions) are, at the "present" moment, proceeding in parallel fashion rather than conjoined; indeed, they need not ever be causally linked. But the possibility does exist that a future act will wed the class/racial abuse to the fledgling workers' organization, thereby altering the significance of both and producing an effect impossible for either singly to induce. Clearly, then, this is a contingency of great potential importance.

We continue with the remaining actions in the chronology below; first, though, we discuss the rationales for the causal imputations we made above.

\section{CAUSAL ASSUMPTIONS AND SYNTHESIZING KNOWLEDGE}

ETHNO's questions are quite obviously premised on temporal order, but, just as obviously, sequence does not necessarily provide answers to them: as was apparent above, we often attribute no causal significance to sequence per $s e$. Thus, the difference between our use of ESA and the cognitive act of following the narrative's unfolding is crucial. The determination of causality is a judgement made by the analyst based on a wide array of evidence and theory rather than a "fact" given naturally by the event's or chronology's temporal order. Indeed, to answer ETHNO's questions, and thereby to causally structure the event, we typically counterfactualized the queries about temporal sequence and then synthesized (i) knowledge of the historical particulars of Local 22, especially those pertaining to RJR, its workforce, and the prior organizing efforts there by unions that were mostly white, (ii) general social theory (e.g. about collective action and social movements), and (iii) historical generalizations of one sort or another (e.g. about race and gender in the Jim Crow South, the CIO's racial policies, comparable unionization drives)..$^{\circ}$

I0. This follows from Max Weber's prescription for the causal analysis of a historical sequence: "The assessment of the causal significance of an historical fact will begin with the posing of the following question: in the event of the exclusion of that fact from the complex of factors which are taken into account as co-determinants, or in the event of irs modification in a certain direction, 
Thus the tools of the generalizing social sciences - from theoretical deduction and historical generalizations to comparison - equipped us with sensitizing concepts, a theoretical foundation on which to rest our answers to ETHNO's queries, and a set of expectations about how the world might be expected to work. But just as narrative sequence did not necessarily determine inferences about historical causation, neither did the application of generalizing logics or strategies. Instead, what was learned or hypothesized through their use was challenged and often modified by the Local 22's particular context, actors and temporality.

To demonstrate this synthesis at work, consider again the first question ETHNO posed ("Does 'Mee: African-American workers meet with UCAPAWA organizers about unionization' require 'Tar: UCAPAWA/CIO target RJR African-American workers for unionization' (or a similar event)?"). Expressing the first action as a historical counterfactual and rephrasing the question a bit, we have the following query: "Would 'UCAPAWA organizers have mer with RJR's African-American workers about unionization' had the 'UCAPAWA/CIO not targeted RJR's African-American workers for unionization'?" To answer this question, we had to refrain from being swept away by the unfolding drama of the narrative, discard the taken-for-granted temporal determination of cause-and-effect implicit in the narrative, and, instead, reason causally. Those requirements, in turn, forced us to consider whether the "targeting" was necessary for the "meeting", sufficient for it, or both necessary and sufficient. We reasoned, though the diagram suggests otherwise, that the targeting was not sufficient grounds for the meeting because, logically, the simple existence of a possibility (the "targeting" strategy) does not generally bring about its own actuality (the meeting between African-American workers and union representatives). The grievances of the workers, too, were instrumental in motivating them to meet with UCAPAWA organizers. But the "targeting" was necessary, we argue, because without it there would have been no supply of union organizers for African-American workers to meet with. Nor, likely, would there have been a demand for them from the rank-and-file. Why? We know that African-American workers were aggrieved by their working

could the course of events, in accordance with general empirical rules, have taken a direction in any way different in any features which would be decisive for our interest?": Weber, The Methodology of the Social Sciences, p. I80 (emphasis in original). The use of the historical counterfactual as the fundamental tool in ESA (and as a useful tool in social science more generally) is advanced in Griffin, "Narrative, Event-Structure Analysis and Causal Interpretation in Historical Sociology". Perhaps the most rigorous recent defense of the use of historically-grounded counterfactuals is contained in Geoffery Hawthrone, Plausible Worlds: Possibility and Understanding in History and the Social Sciences (Cambridge, 1991), esp. pp. 1-37, 157-187. Hawthrone argues that only "plausible" counterfactuals can have inferential value and that they, in turn, should (a) start from the real world as it was otherwise known before asserting the counterfactual, (b) not require us to "unwind the past", and (c) not unduly "disturb" what we otherwise understand about the actors and their contexts. See also Barrington Moore, Injustice: The Social Bases of Obedience and Revolt (New York, 1984), pp. 376-397, for a breathtaking use of the counterfactual. 
conditions and their pay, and that they had previously resorted to small-scale protest, but they generally do not seem to have framed their hardships or possible solutions to those hardships in terms of "union". UCAPAWA organizers crucially shaped the frame - which may be fairly defined as "unionization for the economically and racially oppressed" - through which the workers came to understand both their plight and their possible salvation. So the CIO's initial racial targeting strategy also motivated some of RJR's African-American workers to discuss unionization with representatives of a racially liberal and successful union.

To return now to the general methodological issue under discussion, this simple question, premised on a historically plausible counterfactual, impels historians and social scientists to a close engagement with issues queried. That query also demonstrates that ESA, even as it appropriates narrative sequentiality to formulate its questions, requires the analyst to replace temporal order with her or his knowledge/judgement about causal connections and to examine self-critically the foundation and adequacy of that knowledge.

Altogether ETHNO asked us nineteen questions about the brief chronology (see Table I). Q.2 asked if the "TWOC formation" required the initial "meeting". We responded "Yes", reasoning that the early meetings were necessary both to disseminate UCAPAWA's racial, as well as its class, messages and to build trust with African-American workers, who then made the TWOC a reality by joining it. Q.3-Q.5 were not difficult to answer because, as we noted above, RJR's speed-up, though occurring after UCAPAWA began its drive and formed the TWOC, was (from all available evidence) independent of anything the union was doing. Other questions, particular those also suggesting causal independence (Q.9-Q.14), were also easily answered.

Much more difficult, though, were queries such as Q.8 and Q.15-Q.19, which demanded that we juggle and synthesize generalizations and particularities, often in novel ways, as we moved from question to question. Q.8, for example, asked if "RJR's speed-up" was required for the "abuse of a slow worker". There is no unambiguous answer. On the one hand, a production speed-up is nor generally necessary for such actions because "slow workers" are routinely chastised by their supervisors, and no doubt many at RJR were prior to the speed-up. On the other hand, the speed-up both (i) signified the heightened import RJR placed on "timely" production, and (ii) genuinely made meeting production quotas more difficult. Given this, the probability that some workers would fall behind and would then be punished by supervisors who were themselves both conveying the new production standards and requiring compliance with them was higher than was true previously. All things considered, then, we answered "Yes".

Space limitations preclude discussion of all nineteen questions. But each had the same formal structure as those described above, ${ }^{\mathrm{II}}$ and we relied on

II. The total number of questions depends both on the number of actions in the chronology and the imputed links between them. The more causal imputations follow a simple sequential chain, 
the same general cognitive processes described earlier to address them - that is, we counterfactualized ETHNO's queries and always merged distinct kinds of knowledge and causal and interpretive logics (Verstehen, temporal, theoretic, etc.). After all questions had been answered, the diagram, representing our understanding of how the nine actions constituting the chronology are causally related, is structured as follows:

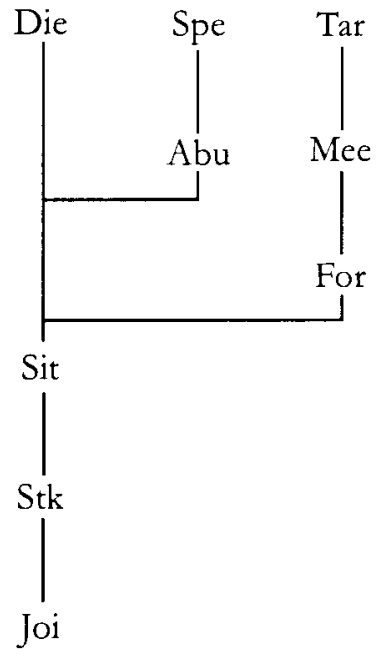

It culminates with the explosive growth of the TWOC during the third week of June 1943 ("Joi", in the chronology and diagram) and shows how this expression of black working-class organization was a consequence of all that preceded it, either directly (the mass strike by thousands of AfricanAmerican workers that followed the sit-down: "Stk") or indirectly (the causal determinants of "Stk", or the determinants of those determinants).

ETHNO contains other helpful routines but the question-and-answer session just demonstrated is, to our way of thinking, the most valuable. ${ }^{12}$ It requires analysts to construct a causal interpretation using their own knowledge and skill and then permits them to examine diagrammatically the logic and implications of that interpretation.

in which action $\mathrm{A} \rightarrow \mathrm{B} \rightarrow \mathrm{C}$, etc., the fewer questions ETHNO asks. Moreover, only direct logical connection is queried; if $\mathrm{A}$ is imputed to be a prerequisite of $\mathrm{B}$, and $\mathrm{B}$ a prerequisite of $\mathrm{C}$, ETHNO will not ask if $A$ is required for $C$. The program knows, by logical implication, that this is so, through the causal influence A exerts on B. Although ETHNO does not directly link A and $C$, the analyst may do so (as we do later in this essay).

12. For example, ESA can assess the logic of the event structure against the program's built-in logic (derived in part from rational choice theory and cognitive anthropology) of how events "ought" to unfold. If a logical discrepancy is discovered, the analyst can choose either to override the diagnostics or alter the event structure to conform to ETHNO's prescriptions. We have found this procedure to be of limited, though occasionally genuine, utility. 


\section{USEFUL FEATURES OF THE ESA ANALYSIS}

Some features of ESA analysis will be of particular use to those scholars with feet in both the historical and social science camps. Using the analysis of the union organizing drive just completed, we briefly discuss four of them below: contingency, complexity, significance and generalization.

\section{Contingency}

Consideration of the reasons for the sit-down strike and how it then quickly led to mass organization adeptly illustrates one of the more important general strengths of ESA, its ability to tease out, display and track the impact of historical contingencies. TWOC's growth ("Joi"), for example, ultimately can be traced back to the UCAPAWA/CIO's early focus on organizing African Americans at RJR ("Tar"), for it was that strategy that both established the possibility of the TWOC's very existence ("For") and led to the meetings between black workers and union organizers ("Mee"). But the diagram (and thus our reasoning) also emphatically denies that mass organization at RJR was either the inevitable or straightforward result of that strategy or of the actions (such as "Mee") that issued directly from it. Indeed, our interpretation suggests that the TWOC would have remained little more than possibility had the sit-down strike by African-American female stemmers not occurred ("Sit"), and that strike, in turn, could not have been predicted from what preceded it or from the extant grievances of the workers. No single structural condition or action, in fact, was sufficient to provoke the sit-down (see the section of the previous diagram relevant to the instigation of the sit-down strike, reproduced below).

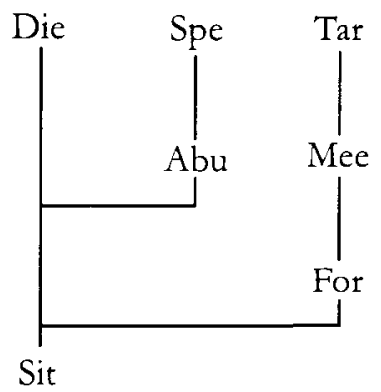

Rather, it was the effect of the complex, contingent (but not necessarily "accidental") confluence of four factors and the meanings female AfricanAmerican workers placed on them: (i) the prior formation of the TWOC among African-Americans workers ("For"), which provided both the organizational base for collective action and an interpretive frame molding and amplifying the racial, gender and class grievances of those who spontaneously stopped production; (ii) RJR's intensified production pace 
("Spe"), which symbolized and exacerbated the long-term grievances of these workers; and (iii, iv) two temporally coterminous, racially-charged "triggering" incidents, the abuse ("Abu") and death ("Die") of black workers.

Neither the sit-down strike nor the mass organization of AfricanAmerican workers which followed "had to" happen; RJR's aggrieved workers could have accepted their lot, protested individually when and as they could, and remained unorganized. ESA helps us understand why both actions did occur nonetheless, and why they happened when they did. And in doing this, ESA thereby helped us grasp how unionization as a structural possibility was transformed by social action into unionization as a lived reality.

\section{Complexity/Density}

Once all of the actions in the chronology have been structured, analysts should examine the diagram with an eye toward seeing if it truly represents their causal and interpretative understandings. If not, ESA permits analysts to alter the structure of the diagram and thereby modify their initial interpretation of the event's unfolding. This seemingly minor technical facility can lead to important substantive and theoretical differences. For example, the "complete" diagram we discussed above (reproduced below)

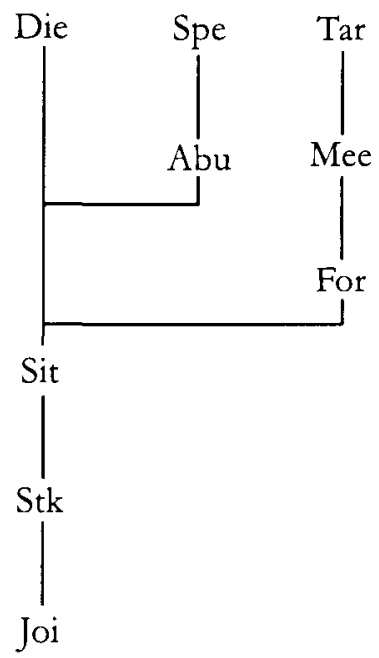

shows quite clearly that among the actions considered here, the only direct determinant of mass membership in the TWOC ("Joi") was the huge strike that preceded it by a few days ("Stk"). That strike, in turn, is seen to have been induced solely by the sit-down strike ("Sit"). In fact, the entire process is represented as simple, unbroken causal chain ("Sit" $\rightarrow$ "Stk" $\rightarrow$ "Joi"). Do we really believe this? In fact, we do not: it is unrealistically voluntaristic, permitting spontaneity to replace organization. Logically, for example, 
African Americans could join the TWOC only because it already existed, so the TWOC's formation ("For") has to be a direct logical prerequisite of "Joi", as well as an indirect causal antecedent (through "Sit"). Through their appeals to discipline, collective courage and racial solidarity, moreover, TWOC members helped sustain (if they did not actually orchestrate) the massive strike spurred by the sit-down ( ${ }^{\text {"Stk" }}$ ); ${ }^{\mathrm{r3}}$ TWOC formation ("For"), therefore, should be considered a direct determinant of the huge strike ("Stk") as well. By linking "For" to both "Stk" and "Joi" in the diagram, we bring into the interpretation the causal weight of pre-existing labor organization, while still permitting the sit-down strike an important role (indeed, as we argue below, a crucial role) in what subsequently happened. The diagram, now revised below, is denser, more complex and, in our opinion, on better theoretical and historical footing.

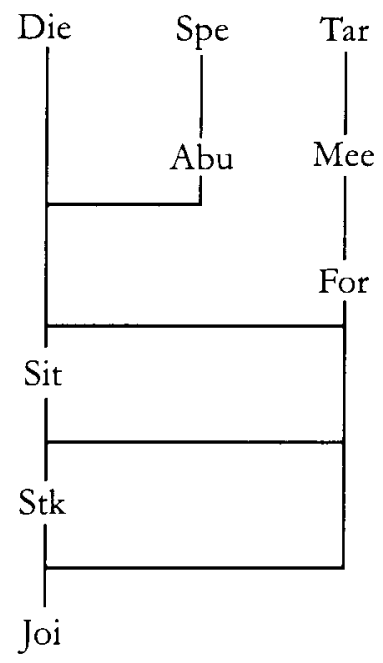

\section{Significance}

Earlier, we noted that the structure of ESA's diagrams had substantive import and meaning. These interpretive structures may also be used by the analyst to visualize and thereby better judge the historical significance of particular actions in the event. One way to define "historical significance" in a precise sense is in terms of how an action links past and "present", thereby transmuting the former into the latter, and/or how it portends possible courses of action in the future. Significant actions need not necessarily represent "turning" or "switch" points in the history of an event (these are actions that shunt the event from one sequential path to another),

13. Griffin and Korstad, "Class as Race and Gender". 
but they are actions of heightened consequence to the entire sequence because they both serve as the repository of previous actions and funnel the causal force of that past onto subsequent actions, thereby establishing future possibilities.

In the diagram of the UCAPAWA organizing drive, each action is indispensable; there are no truly irrelevant actions, and no historical "dead-end" paths that terminate without consequence. But some actions, nonetheless, are more equal than others. In the chain of historical causation, for instance, union organization at RJR was the culmination of actions instigated by the sit-down strike ("Sit") by African-American females. That action pivotally linked the CIO's national strategy ("Tar") of organizing African Americans, and chronic (e.g. the production speed-up: "Spe") and unforeseen grievances (the racial abuse ("Abu") and death ("Die")), on the one hand, to the thousands of potential African-American unionists at RJR (“Joi"), on the other. The sit-down proved to be the means through which both UCAPAWA institutionalized its presence at Reynolds and African Americans gained, at least for number of years, a powerful voice in the company and in WinstonSalem. ${ }^{14}$ Thus can ESA be wielded to peel back layers of significance buried in conventional historical narratives.

\section{Generalization}

The analyst may also formally generalize an event's initial, "concrete" logical structure (i.e. those, such as the ones we develop in this essay, that stay very close to, and reproduce analytically, the historical particulars of the event). In this routine (known as "instantiation" in ETHNO), actions in the "concrete" structure are viewed as empirical "instances" of theoretically general concepts and the analysis, still sequential in its interrogatory logic, proceeds at a "higher", theoretically more explicit, level of generality.

Were we to filter the early history of Local 22 through the conceptual lens of general social movement theory, for example, both the first and second actions in the chronology ('UCAPAWA/CIO target RJR's AfricanAmerican workers for unionization", and "African-American workers meet with UCAPAWA organizers about unionization") might be generalized in meaning and restated as a single action, "Social movement organization (SMO) formulates strategy for interracial organization"; the third action ("UCAPAWA forms all-black TWOC to include strategically placed workers") redefined as "SMO deepens organization resources"; the fourth action ("RJR speeds up production process") generalized to "SMO's target intensifies movement constituency's grievances", and so on. Only those "concrete" actions thought to "instantiate" pertinent theoretical concepts (pertinent to a given theory, that is) would be generalized in meaning and 
thus included in the more parsimonious "general" chronology. This chronology would then be subject to the same sort of question-and-answer routine described earlier. Hence, ETHNO would ask if "SMO deepens organization resources" requires "Social movement organization (SMO) formulates strategy for interracial organization". The analyst's responses, now rooted in historical generalizations and theoretical expectations rather in event particulars, again would be diagramed by ETHNO as ESA began to build a "general" event structure.

Though perhaps of greater utility to the generalizing social scientist than the historian, ESA's proficiency with multiple levels of analysis (and with structuring a tight dialogue between them) is worthwhile to any scholar interested in the broader empirical applicability and conceptual meaning of her or his research. In the hypothetical analysis just described, for example, Local 22's early history is used to construct a "general" causal interpretation of movement-building and that representation, in turn, could be explicitly compared to abstract event structures derived from the historical experiences of other union organizing campaigns and even entirely different kinds of social movements (civil rights and women's movements, etc.).

ESA's "instantiation" routine, finally, is useful even to those who do not wish to extend theoretically or empirically the scope of their analysis beyond the historical particulars of the single event. It can assist them in aggregating similar actions and in otherwise reducing the length of the "concrete" chronology, and it can deepen their conceptual understanding of the specific actions. Because the causal reasoning embedded in the two interpretations can be tested for logical consistency, moreover, ESA can also help analysts detect points in the interpretation where their "concrete" understanding of what happened differs from (or even contradicts) their "general" understanding. In his ESA analysis of a 1930 white-on-black lynching, for example, Griffin uncovered and corrected important substantive problems in his "concrete" causal interpretation because of a logical discrepancy between it and his "general" event structure. ${ }^{15}$ Thinking "generally", then, can profoundly enhance thinking "particularly".

\section{CONCLUSION}

ESA is a flexible analyrical tool: it can be bent to more "theoretical" or more "historical" purposes (to the extent that these really are different or opposite); it can focus intensely on a singular happening or it can be deployed for systematic comparison; it can incorporate the actions of virtually any actor - from living individuals to those of a corporate (e.g. RJR) and collective (e.g. sit-down strikers) nature - and it can be used

I5. Griffin, "Narrative, Event-Structure Analysis and Causal Interpretation in Historical Sociology". 
to unpack events of virtually historical scope or duration, from the most geographically and temporally circumscribed to those unfolding over large blocks of space and time.

It is also an unusual tool in that it requires the analyst to merge disparate ways of thinking and knowing in order to unpack an event and construct a compelling, historically-grounded causal interpretation of it. If we are to grasp the general in the particular, and the abstract and logical in the chronological - and these are crucial aspects of what the "unpacking" of a narrative entails - we must avoid social science reductionism as well as pure narrativism. Social science explanations of historical events too often rest on and are content with the imposition on history of ahistorical general theory rather than on serious engagements with historical complexity and specificity. Too often what theoretically general social science brings to historical questions are pseudo-explanations, bereft of real utility and often bereft of even the possibility of empirical disconfirmation. But a "return to narrative ${ }^{n},{ }^{16}$ if that is understood as merely telling a story, is, as we have documented, also unacceptable as the basis for crafting replicable causal interpretations of events. The real historical utility of narrative, we think, hinges more on viewing its sequences as "witness" to and "testimony" about historical events than as analytically rigorous interpretive accounts of why happenings occurred as they did.

ESA, in contrast, demands what E.P. Thompson has called a "disciplined dialogue" between theory and evidence. ${ }^{17}$ In particular, it mandates near constant "particularization" of the theoretically general ("what bearing does this generalization have for this particular action? for this particular event?") and the "generalization" of the historically particular ("what is the general meaning and significance of this action? what generally induces action of this sort?"). Narrative is buttressed by ESA's analytical self-consciousness, then, just as social science methodology is historicized in purpose and practice.

None of this is to suggest that ESA is without its own problems, both pragmatic and otherwise. One practical limitation, for instance, is that effective application of ESA becomes quite difficult, and the ETHNO diagram visually chaotic, if chronologies contain a great many statements (roughly, beyond fifty). As we noted earlier, however, analysts are encouraged to range far beyond the chronology as they interpret and structure the event. Chronologies can remain relatively short with no loss of essential information.

16. Compare, for example, Lawrence Stone, "The Revival of Narrative: Reflections on a New Old History", Past and Present, 85 (1979), pp. 3-24, with Eric Hobsbawm, "The Revival of Narrative: Some Comments", Past and Present, 86 (1980), pp. 3-8.

17. Thompson, The Poverty of Theory, p. 43. 
Quite likely much more formidable barriers to widespread adoption of ESA are disciplinary conventions and prejudices. Social scientists are apt to suspect ESA is much too similar to the practice of history because it is too "subjecrive" and too focused on particularity and complexity. Though largely incorrect, this belief is unlikely to be overthrown as long as sociologists and others are invested in scientistic epistemologies of social inquiry. ${ }^{18}$ Historians, on the other hand, may believe ESA excessively formal and "model-driven". This belief, too, is unfounded: event structures are not theoretical models imposed on the historical record, but nothing more than explicit depictions of the analyst's interpretations. ESA does not mechanically spit out answers to pressing historical questions, and causality, significance and meaning are not "discovered" through its use. It assumes that the analyst, not the algorithm, possesses the requisite knowledge to anticipate possibilities in a sequence of unfolding action, counterfactualize questions and conditions, explain what happened and interpret meaning. Thus the hard work of interpreting causality and extracting meaning from the event falls, as always, to the investigator.

Nor should historians fret that ESA destroys the tension and drama of narrative flow, reduces "real" persons to theoretical stick-figures, or weighs the story down with needless technicalities and incomprehensible jargon. Because ESA is, first and foremost, for scholarly self-edification - that is, to sharpen, deepen and broaden the analyst's own thinking - the fruits of an ESA analysis need not be present in the text nor impede stylistic facility. ${ }^{19}$ The research product would look and read much like any conventional narrative history: it would simply be better history.

To argue, finally, that ESA is irrelevant to the narrativist because causal or interpretive methodology is itself unnecessary begs the issue: all historical inquiry is of necessity indelibly stamped by the methodological presuppositions and practices brought to the research. The real questions to confront, then, are not whether or not to use methodology, but what methodologies to use, how to use them and for what purpose, and how to communicate what was learned from their use. Few methodologies, formal or informal, either demand or offer so much in these respects as does event-structure analysis.

18. See, for example, the extended rebuttal to these and similar criticism of ESA (and interpretive methods more generally) by Griffin and Ragin, "Some Observations on Formal Qualitative Analysis".

19. As previously stated, though our substantive analysis of Local 22 was grounded in ESA, as was the narrative organization of our interpretation, we did not present either the analysis or any of its collateral details (the diagram, etc.). ESA functioned as the unobserved logical backbone of what appeared stylistically to be conventional narrative history: see Griffin and Korstad, "Class as Race and Gender". 


\section{ANNOTATED BIBLIOGRAPHY \\ Foundations of Event-Structure Analysis}

Event-structure analysis was developed by sociologist David Heise. Though devoid of any linkage to historical inquiry/reasoning, he and his colleagues' early expositions of the methodology are detailed, generally accessible, and essential to all who consider ESA.

Corsaro, William and David Heise, "Event Structure Models from Ethnographic Data", Sociological Methodology, I990 (I990), pp. I-57.

Heise, David, "Computer Analysis of Cultural Structures", Social Science Computer Review, 6 (1988), pp. 183-196.

Heise, David, "Modeling Event Structures", Journal of Mathematical Sociology, I4 (1989), pp. 139-169.

Heise, David, and Elsa Lewis, Introduction to ETHNO (Raleigh, NC, 1988). This is the ESA-ETHNO computer manual; it is invaluable.

\section{ESA and Historical Reasoning}

Griffin, Larry J., "Narrative, Event-Structure Analysis and Causal Interpretation in Historical Sociology", American Journal of Sociology, 98 (I993), pp. I094-II33.

This was the first, and still most fully developed, attempt to wed ESA's logic and mode of operation to issues of causal interpretation, narrative, historical causation, comparative method, etc. Much of the article is devoted to the explication of ESA and includes a long, detailed substantive application of ESA to a 1930 lynching in Mississippi.

\section{ESA: Applications, Explorations and Extensions}

Brown, Cliff and John Bruggemann, "Mobilizing Interracial Solidarity: A Comparison of the 1919 and 1937 Steel Industry Labor Organizing Drives", Mobilization, 2 (1997), pp. 47-70.

Using ESA, Brown and Bruggemann formally compare the eventstructures of the two organizing drives in steel to comprehend better why one failed (1919) and one succeeded (1937).

Griffin, Larry J. and Robert R. Korstad, "Class as Race and Gender: The Making and Breaking of a Union Local in the Jim Crow South", Social Science History, 19 (1985), pp. 425-454.

In our previous publication on Local 22, we relied on but did not report the ESA analysis. This example thus shows how ESA may be used solely as a heuristic aiding the analyst to interpret the event and to structure her or his narrative of its history.

Griffin, Larry J., Paula Clark and Joanne Sandberg, "Narrative and Event: 
Historical Sociology and Lynching", in Fitzhugh Brundage (ed.), Under Sentence of Death: Lynching in the New South (Chapel Hill, NC, 1997).

Griffin et al. argue that ESA is a useful tool to understand why some "lynchings-in-the-making" were averted and others completed.

Isaac, Larry, Debra Street and Stan Knapp, "Analyzing Historical Contingency with Formal Methods: The Case of the 'Relief Explosion' and 1968", Sociological Methods and Research, 23 (1994), pp. II4-I4I.

Isaac et al. productively apply ESA to an unusual "event", the tumultuous year 1968.

Kiser, Edgar, "The Revival of Narrative in Historical Sociology: What Rational Choice Can Contributen, Politics and Society, 24 (1996), pp. 249-27I.

Criticizing much of the "new narrativism" in sociology for its inductivism, Kiser urges the wedding of narrative analysis (including ESA) to a powerful deductive frame, rational choice theory. 